RESEARCH REPORT

\title{
ASSESSMENT OF DIFFERENCES IN VITAMIN C INTAKE BEFORE AND DURING RAMADAN AMONG GENERAL POPULATION IN KARACHI
}

\begin{abstract}
\section{BACKGROUND}

Inconsistent data revealed on investigation of nutrient intake by different populations of Muslims during Ramadan, particularly due to the variations in dietary norms.

\section{OBJECTIVES}

The purpose of this observational study was to find out the difference of Vitamin $C$ intake before and during Ramadan within different age groups and genders.

\section{METHODS}

A prospective study was conducted to investigate Vitamin C intake of subjects on two occasions: before and during Ramadan. A total of 770 voluntary subjects (12-90 yrs.) were enrolled for the research. Informed consent form was obtained from each of the participant before the commencement of the study. A quantitative questionnaire cum interview method was used to collect demographic data, health characteristics and dietary intake data. Dietary data was collected using a 24 hour dietary recall and Generic Food Photograph Atlas (GFP) while food items were recorded in codes. Standardized Recipes were used to assess the amount of Vitamin C in each food consumed. Vitamin $C$ intake was calculated with the help of the United States Department of Agriculture Food Composition Table (USDA FCT) and Allama labal Open University Food Composition Table (AIOU FCT). Analysis was conducted using Paired-T-Test and MANOVA using Statistical Package for Social Sciences (SPSS) Software, Version 16.

\section{RESULTS}

A significant increase was observed in the overall intake of Vitamin $C$ in the diet of participants during Ramadan $1195.5 \%$ of before Ramadan intake). Moreover, the results indicated that Vitamin C consumption was increased among both males and females $(\mathrm{P}=$ $<0.05)$ and among heterogeneous aged subjects during Ramadan $(\mathrm{P}=<0.05)$.
\end{abstract}

\section{CONCLUSION}

Additional research is warranted to further elucidate the increased intake of Vitamin $\mathrm{C}$ with regards of cultural differences.

\section{KEYWORDS}

Vitamin C, Before Ramadan, Intake, Generic Food Photograph Atlas, During Ramadan, Karachi

\author{
Marium Sheikh \\ Sr. Therapeutic Dietitian \\ Department of Preventive \\ Cardiology and Cardiac Rehabili- \\ tation \\ Tabba Heart Institute \\ mariam.sheikh@tabbaheart.org

\section{Dr. Farzana Amir Hashmi} \\ Deputy General Manager, HOD \\ Preventive Cardiology and \\ Cardiac Rehabilitation \\ Tabba Heart Institute \\ farzana.hashmi@tabbaheart.org
}

[Sheikh M \& Hashmi FA. Assessment of differences in Vitamin $C$ intake before and during ramadan among general population in Karachi. Pak. j. rehabil. 2016;5(1):25-30] 


\section{INTRODUCTION}

The fact has been observed that an individual is not consuming any food or drink for more than 8 hours and still is able to do their annual routine creates curiosity and interest in the researching world. However, there is a dichotomy research objective amongst researchers who are interested in observing the Ramadan fast ${ }^{1}$. Circadian changes are associated with Ramadan timings ${ }^{2}$ and twenty four hours recall is efficient to record dietary data of an individual within twenty four hours ${ }^{3}$ with coded food records ${ }^{4}$ and food recipes ${ }^{5}$. Among all nutrients vitamin $C$ is one of the nutrient which can be assessed by the United States Department of Agriculture Food Composition Table (USDA FCT) ${ }^{6}$ and Allama labal Open University Food Composition Table(AIOU FCT ${ }^{7}$. As the Different Islamic populations have different alimentary habits, notably during Ramadan ${ }^{8}$, most researchers conduct their research on Ramadan a priory to get some negative effects of Ramadan to the Muslim subjects?. Moreover, there are some researchers who conduct the study in the mere interest of the occurring changes in the dietary pattern, nutrient intake and activity amongst fasting subjects during the Ramadan month ${ }^{10-12}$.

Although religious fasting is often a time of great spiritual growth, it can also be a time of great improvement to one's physical health and perhaps to lose weight'13. Ramadan brings about changes in the life style ${ }^{14}$, sleep hours ${ }^{15}$, physical activities ${ }^{16}$, food consumption, meals frequencies and dietary habits for different reasons among Muslims ${ }^{17-20}$. Fasting has been the subject of numerous scientific investigations $^{17,18}$ and the general opinion is that fasting has a potential of non-pharmacological intervention for improving health and increasing longevity ${ }^{18}$. It is assumed that such variations may be related to the quality and quantity of foods ingested by Muslims in various countries and sub-cultures ${ }^{21}$.

During Ramadan fast, the time and amount of meal taken by Muslims are completely altered. After a long day of fast, they experience a higher degree of hunger compared to normal days when food intake is allowed anytime of the day'. Muslims consume a greater variety of food during Ramadan compared with the rest of the year ${ }^{22}$. Also, sugary foods and drinks are consumed more frequently during Ramadan ${ }^{23}$. Similar observation of increased food consumption in Ramadan was noticed in several studies ${ }^{17,24}$. Although there was a significant reduction in meal frequency and the number of meals taken outside the family, a significant increase in body weight was noted during Ramadan $^{24}$. Change in eating habits during Ramadan is in the form of reduction in frequency of food and fluid intake, and increased tendency to consume higher calorie foods and drinks ${ }^{14,25,26}$.
A combination of food choices made by an individval will create a dietary pattern that is either healthy or unhealthy. These dietary choices can be influenced by many factors surrounding an individual, e.g. religion, socioeconomic factor and education level'. Therefore, people who are explored to different conditions will develop a unique dietary pattern depending on the needs and adaptation to the surrounding environment ${ }^{1}$.

It was previously thought that Ramadan fasting often led to reduced energy intake and weight loss $^{22}$, but recent studies have found that caloric intake actually increases despite the decreased meal frequency ${ }^{27}$. Regarding the latter, El-Ati et al. reported that the total energy intake increased among Saudi subjects and decreased among Indian subjects during Ramadan, and that this discrepancy was due to the differences in food choices between the two groups ${ }^{2}$. Hence, the majority of findings related to Ramadan fasting is mixed, and these discrepancies are most likely due to the differences in cultural norms - particularly dietary norms - of the groups which have been studied ${ }^{17}$. Cultures and sub-cultures differ in their socio-economic backgrounds and dietary habits in Ramadan $^{13}$. Future investigations should take these variables as well as other confounding variables into consideration.

Investigations of the energy intake and body composition changes during the month of Ramadan showed different findings which are may be due to the different nutritional customs and habits and also the length of fasting 22,28 . Daily fasting time varies from 10 to 18 hours $^{10,29}$ according to the time of the year that Ramadan occurs as well as the geographical location ${ }^{17}$. Hence, the duration of fast may affect one's intake of nutrients.

Aside from macronutrients, vitamins and minerals are generally consumed in similar amounts during Ramadan ${ }^{17}$. On the other hand, Suriah \& Zarina found no significant difference in the energy and nutrient intakes of elderly subjects between the fasting and non-fasting months ${ }^{30}$. On the contrary, Zerguini et al concluded that Ramadan fast had small effects on the diet composition and the changes will bounce back to pre-Ramadan levels after the fasting month ${ }^{31}$. Whereas, in Tunisia Ramadan is always associated with an increased consumption of fruits, salads, eggs, milk, and other dairy products ${ }^{8}$. Gharbi M, 2003, stated that the meal eaten after sunset was an important contributor to calories (65\%), lipids $(74 \%)$, proteins $(71 \%)$ and carbohydrates (56\%). These findings showed that the eating behavior during Ramadan may contribute to improved nutritional status of people at risk of nutritional deficiency ${ }^{32}$. Collectively, the literature indicates that dietary changes pertaining to kcal intake, as well as macro- and micro-nutrient intake, may or may not differ over the period of Rama- 
dan $^{17,33,34}$

Vitamin $\mathrm{C}$ is an essential micronutrient required for normal metabolic functioning of the body ${ }^{35}$. The Vitamin $\mathrm{C}$ is especially plentiful in fresh fruits, particularly citrus fruits, and vegetables ${ }^{36}$. Many biochemical, clinical, and epidemiologic studies have indicated that Vitamin C may be of benefit in the prevention of chronic diseases such as cardiovascular disease, cancer, and cataract. This role of Vitamin $\mathrm{C}$ in lowering disease incidence is most likely derived from its antioxidant activity, although other mechanisms may also contribute. As such, the potential of adequate Vitamin $C$ nutrition to benefit public health and reduce the economic and medical costs associated with these chronic diseases is enormous ${ }^{37-39}$.

Ramadan fasting is characterized by alterations in meal schedule and frequency. Meals are exclusively nocturnal and less frequent; hence this may affect energy and nutrient intake ${ }^{1,22}$. Even Muslims consumea greater variety of food during Ramadan compared with the rest of the year ${ }^{22}$. Inconsistent data revealed on investigation of Vitamin C intake by different populations of Muslims during Ramadan, particularly due to variations in dietary norms ${ }^{1,2}$. The current investigation, therefore, was carried out to assess Vitamin C intake before and during Ramadan in order to find out the difference of Vitamin $C$ intake before and during Ramadan and to reveal the difference of Vitamin $C$ intake among different age groups and genders.

\section{METHODOLOGY}

Initially, a total of 997 subjects were approached in different areas of Karachi, but only 770 volunteers completed the full protocol. No boundaries were set related to the prevalence of any disease, drug addiction, ethnicity or sex for subjects' enrollment. Only those subjects (> 12 yrs.) were recruited for the study that would fast during Ramadan and would also be available for Ramadan data collection as well.

To assess the intake of participants before and during Ramadan, the data was collected in two phases: (1) before Ramadan (2) during Ramadan. A quantitative questionnaire method was used. The data collection was conducted at subjects' home, over the telephone or through Skype. Informed consent was obtained from each of the participant before the commencement of the study. The efficacy of questionnaire was assessed through pre-testing in order to measure the extent of desired outcomes and pertinent results. A few questions were then revised and re-phrased.
A food list was established considering the common food items consumed by general population. Each food item included in the food list was given a specific code. There were around 311 food items in the list which were coded from 1-311. These codes were then used during data collection to reduce the excess time spent in data collection.

An open-ended interview guide was designed that contained questions on demographic characteristics lage, gender, and marital, educational and work status), health characteristics and the presence of any addiction of non-food items (pan, gutka, chalia, sheesha etc). Information of the previous day's food consumption pattern was gathered with the aid of a 24 hour dietary recall.

A 2-dimensional Generic Food Photograph (GFP) Atlas ${ }^{3}$ was used to assess the accurate amount of food consumed by selecting household measures via pictures. The data was entered in SPSS, Version 16.

About 281 food items were consumed by the respondents. The pictures selected by the respondents from the GFP Atlas showed the volume of food consumed. The volume obtained was then multiplied to the density of specific food item to get the actual weight of food consumed. Standardized recipes ${ }^{4,5}$ were used to calculate the content of Vitamin C per $100 \mathrm{gm}$ of food with the help of USDA 6 and $\mathrm{AlOU}^{7}$ food composition data tables. The missing data was detected and deleted. To apply the multivariate analysis of variance (MANOVA), the uneven distribution of the data was normalized by using the square root method of transformation. The level $P \leq 0.05$ was considered as the cut-off value for significance. Data were presented using descriptive statistics in the form of frequencies and percentages for quantitative variables. Paired Sample T Test was used to compare mean intake of Vitamin C before and during Ramadan. Multivariate Analysis of Variance - MANOVA was used to determine the differences in intake among genders and within age groups (12 to 19 yrs., 20 to 64 yrs. and 65 to $90 y$ rs.). The demographic results are presented in tables and graphs. The comparisons of Vitamin C intake ( $\mathrm{mg} /$ day) before and during Ramadan are presented in charts. Intakes are presented as mean \pm SD.

\section{RESULTS AND DISCUSSION}

The results revealed that the majority of subjects were females. Adults (20-64 yrs.) were found to be in a higher proportion. The demographic characteristics of the subjects are summarized in Table 1. 


\begin{tabular}{|c|c|c|}
\hline \multicolumn{3}{|c|}{$\begin{array}{l}\text { Table 1: Demoghraphic Characteristics of Study } \\
\text { Sample }(n=770)\end{array}$} \\
\hline Demographic Variables & $\begin{array}{l}\text { Number } \\
(\mathrm{N})\end{array}$ & $\begin{array}{l}\text { Percentage } \\
\text { (\%) }\end{array}$ \\
\hline \multicolumn{3}{|l|}{ Gender } \\
\hline - Male & 306 & 39.7 \\
\hline - Female & 464 & 60.3 \\
\hline \multicolumn{3}{|l|}{ Age Group } \\
\hline - $12-19$ yrs. & 161 & 20.9 \\
\hline - 20 - 64 yrs. & 564 & 73.2 \\
\hline - $\quad 65-90$ yrs. & 45 & 5.8 \\
\hline
\end{tabular}

\begin{tabular}{llc} 
Work Status & & \\
- Students & 237 & 30.8 \\
- Employed & 257 & 33.4 \\
- Unemployed & 43 & 5.6 \\
- House Wife & 33 & 30.3 \\
\hline
\end{tabular}

Marital Status

- Married

$$
410
$$

- Unmarried

41.7

- Discovered

9

1.2

- Widow/ Widower

30

3.9

Values are expressed in number and percentage.

The results (Figure 1) showed that the participants of this study had varied levels of education. The higher

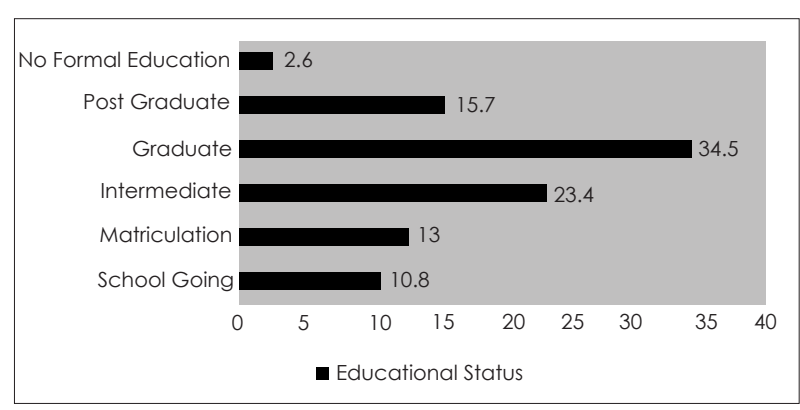

Figure 1: Educational Status of Study Sample $(n=770)$ Values expressed in perentages.

proportion of respondents was of graduates. Regarding the health status, results (Figure 2) revealed that $63.9 \%$ of the participants were healthy without any health problem or disease. While, among those with health issues the highest proportion was of hypertensive subjects.

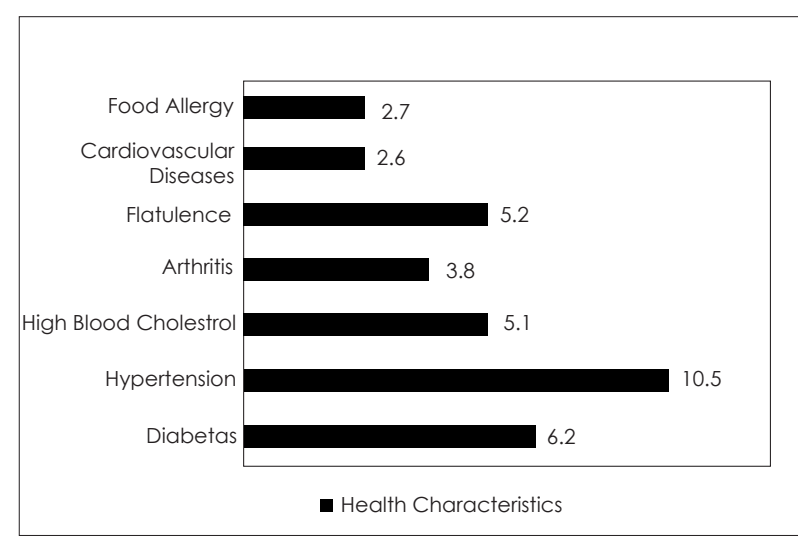

Figure 2: Health Characteristics of Study Sample $(n=770)$ Values expressed in perentages.

The test findings revealed that the consumption of Vitamin C among participants (Figure 3) was roughly doubled during Ramadan (DR). The results concluded a significant increase in the intake of subjects, which was as much as $195.9 \%$ of before Ramadan (BR) intake.

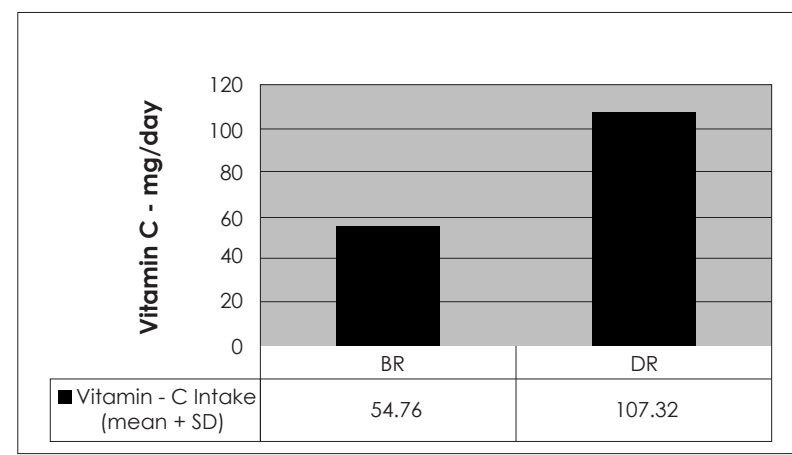

Figure 3: Comparison of Vitamin - $C$ Intake before and during Ramadan (n-770)

$p$-value $=0.00$. Means significantly increased DR.

The results did run contrary to previous findings which showed that Vitamin $C$ intake remained unchanged during Ramadan ${ }^{17,31}$. Ramadan fasting is characterized by alterations in meal schedule and frequency. After a long day fast, people experience a higher degree of hunger compared to normal days when food intake is allowed anytime of the day '. Accordingly, current findings showed that the total Vitamin-C intake was significantly increased DR compared with the BR period. The results concluded that Vitamin $C$ consumption was significantly increased across all age groups DR (Figure 4). Adolescents (12-19yrs.), on comparison, had a greater increase in intake DR (as much as $212.5 \%$ of the $B R$ ) than the remaining two age 
groups.

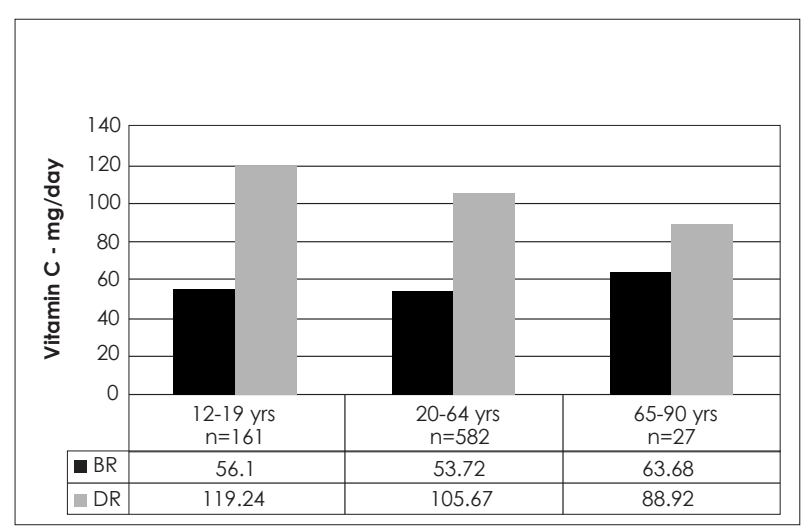

Figure 4: Comparison of Vitamin - C Intake before and during Ramadan across age-groups $(\mathrm{n}=770)$

$P$-value $=0.00$; values expressed in mean $\pm S D$. Mean significantly increased DR.

The findings of this study violate Suriah \& Zarina research results that concluded a non significant difference in the energy and nutrient intakes of elderly subjects between the fasting and non-fasting months ${ }^{30}$. It could be attributed to the fact that people who fast is likely to over-compensate their fluid and food intake during non-fasting hours in Ramadan. Hence, they experienced increase in their total Vitamin-C content in diet during Ramadan.

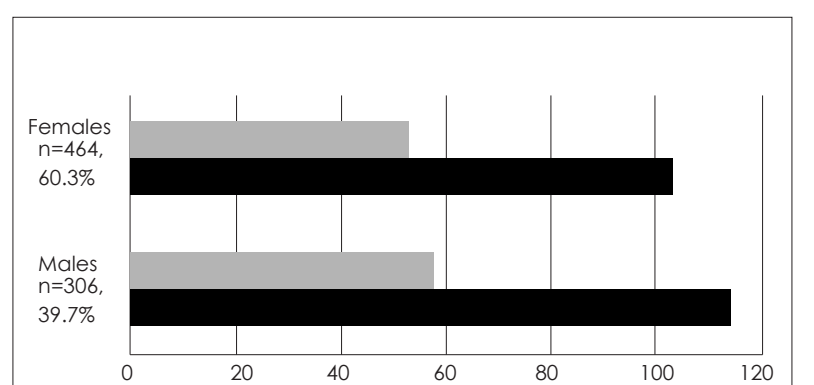

\begin{tabular}{|c|c|c|}
\cline { 2 - 3 } \multicolumn{1}{c|}{} & Males & Females \\
\hline BR & 57.91 & 52.85 \\
\hline$\square$ DR & 114.06 & 103.02 \\
\hline
\end{tabular}

Figure 5: Comparison of Vitamin - C Intake before and during Ramadan with in genders $(n=770)$

P-value=0.00; expressed in mean $+S D$. Means Significantly increased DR.

The results (Figure 5) revealed that among males and females, the content of Vitamin- $C$ in their diet was markedly increased DR compared to their BR intake. A previous study conducted in Tunisia concluded that Ramadan is always associated with an increased consumption of fruits, salads, eggs, milk, and other dairy products ${ }^{8}$. The present study results validate it with the fact that the Vitamin C intake was raised among respondents with increased consumption of Vitamin C rich foods such as fruits.

\section{CONCLUSION}

The results of this study concluded that Vitamin C intake during the month of Ramadan was signifi- cantly increased among both males and females, and within all age groups. Therefore, Ramadan in Pakistan is associated with a marked increase in the intake of Vitamin $\mathrm{C}$. The findings in this small-scale cohort study indicate the need for more studies to further elucidate the increased intake of Vitamin C with regards of cultural differences. Identifying the dietary patterns of specific communities and cultural alimentary habits can help to better understand which food choices are contributing to an improved Vitamin $\mathrm{C}$ intake so they could then be addressed in nutrition education programs offered in the community or at national levels.

\section{REFERENCES}

[1] Zakaria NM. Dietary pattern and nutritional intake amongst female university students observing the Ramadan fast. [internet]. [cited 2016]. Available from: http://eprints.ums.edu.my/4161/1/ae0000000571.pdf

[2] El Ati J BC. Increased fat oxidation during ramadan fasting in healthy women: an adaptative mechanism for body-weight maintenance. Am J Clin Nutr. 1995;62(2):302-307

[3] Hakeem R, Asar F. Generic food photograph atlas. Karachi: HAN Sons; 2011

[4] Feroz S: Thesis Recipes. Retrieved $22^{\text {nd }}$ September 2012

[5] CHE Analyzed Recipes. 20 ${ }^{\text {th }}$ September 2012

[6] U.S. Department of Agriculture. Agricultural Research Service. [internet]. [updated 2012, cited 2016]. USDA National Nutrient Database for Standard Reference. Available from http://ndb.nal.usda.gov

[7] Allama labal Open University. Food composition table for Pakistan. [internet]. [cited 2016]. Available from: http://www.aiou.edu.pk/foodsite/FCTViewOnLine.html

[8] Bakaria A, Mohamed K, Smaoui M, Zouari N, Hammami M, Nasri M. Change of diet, plasma lipids, lipoproteins, and fatty acids during ramadan: a controversial association of the considered ramadan model with atherosclerosis risk . J Health Popul Nutr. 2011 ;29(5):486-493

[9] Reilly T, Waterhouse J. Altered sleep-wake cycles and food intake: the ramadan model. Physiol Behav. 2007;90(2-3):219-228

[10] Meckel Y, Ismaeel A, Eliakim A. The effect of the ramadan fast on physical performance and dietary habits in adolescent soccer. Eur J Appl Physiol. 2008;102(6)651-657

[1 1] Mahdavi R, Balaghi S, Maghmi SJG, Faramarzi E, Shiri F, Zadeh NK. Energy and fluid intake among university female students during and after holy ramadan month. Pakistan J Nutr. 2009:8(1):96-99

[12]Poh B, Zawiah Z, Ismail M, Henry C. Changes in body weight, dietary intake and activity pattern of adolescents during ramadan. Malays J Nutr. 1996;2(1):1-10

[13]Bakhotmah BA. The puzzle of self-reported 
weight gain in a month of fasting (ramadan) among a cohort of Saudi families inJeddah, Western Saudi Arabia. Nutr J. $2011 ; 10(84): 1-8$.

[14] Toda M, Morimoto K. Effects of ramadan fasting on the health of muslims. Nihon Eiseigaku Zasshi. 2000;54(4):592-596.

[15] BaHammam AS. Does ramadan fasting affect sleep? Int J Clin Pract. 2006;60(12):1631-1637

[16] Chaouachi A, Leiper JB, Souissi N, Coutts AJ, Chamari $K$. Effects of ramadan intermittent fasting on sports performance and training: a review. Int $\mathrm{J}$ Sports Physiol Perform. 2009;4(4):419-434

[17] Trepanowski JF, Bloomer RJ. The impact of religious fasting on human health. Nutr J. 2010;9:57

[18] Azizi F. Islamic fasting and health. Ann Nutr Metab. 2010;56:273-282

[19] Yakoob MY. Fasting during ramadan and obesity. Saudi Med J. $2011 ; 61$ (3):303

[20] Guerrero Morilla R, Ramírez Rodrigo J, Sánchez Caravaca A, Villaverde Gutiérrez C, Ruiz Villaverde G, Pérez Moreno BA. Dietary modifications, in young Muslims engaged in ramadan fasting. Nutr Hosp. 2009;24(6):738-743

[21] Khaled BM, Belbraovet S. Effect of ramadan fasting on anthropometric parameters and food consumption in 276 type 2 diabetic obese women. Int $J$ Diabetes Dev Ctries. $2009 ; 29(2): 62-68$

[22] Hallak MH, Nomani MZ. Body wieght loss and changes in blood lipid levels in normal men on hypocaloric diets during ramadan fasting. Am J Clin Nutr. 1988;48(5):1 197-1210

[23] Fedail SS, Murphy D, Salih SY, Bolton CH, Harvey RF. Changes in certain blood constituents during ramadan. Am J Clin Nutr. 1982;36(2):350-353

[24] Frost G, Pirani S. Meal frequency and nutritional intake during ramadan: a pilot study. Hum Nutr Appl Nutr. 1987;41 (1):47-50

[25] Ziaee V, Razaei M, Ahmadinejad Z, Shaikh H, Yousefi R, Yarmohammadi L, Bozorgi F, Behjati MJ. (2006). The changes of metabolic profile and weight during ramadan fasting. Singapore Med. 2006;47(5):409-414

[26] Memari AH, Kordi R, Panahi N, NikookarLR, Abdollahi M, Akbarnejad
A. Effect of ramadan fasting on body composition and physical performance. Asian J Sports Med. $2011 ; 2(3): 161-165$.

[27] Lamine F, Bouguerra R, Jabrane J, Marrakchi Z, Ben Rayana MC, Ben Slama C, Gaigi S. Food intake and high density lipoprotein cholesterol levels during ramadan fasting in healthy young subjects. Tunis Med. 2006;84(10): 647-650

[28] Roky R, Chapotot F, Hakkou F, Benchekroun MT, Buguet A. Sleep during ramadan intermittent fasting. J Sleep Res2001;10(4):319-327

[29] Al-Hourani HM, Atoum M. Body composition, nutrient intake and physical activity patterns in young women during Ramadan. Singapore Med J. 2007;48(10):906-910

[30] Suriah AR, Zarina N. A comparative study on the nutritional status and activity pattern of fasting and non-fasting elderly. Proceedings of the 5th ASEAN Food Conference. Kuala Lumpur;1994

[31] Zerguini Y, Kirkendall D, Junge A, Dvorak J. Impact of ramadan on physical performance in professional soccer players. J Sports Med. 2007;41 (6):398-400

[32] Gharbi M, Akrout M, Zouari B. Food intake during and outside ramadan. East Mediterr Health J. 2003;9(1-2):131-140

[33] Ibrahim WH, Habib HM, Jarrar AH, AlBaz SA. Effect of ramadan fasting on markers of oxidative stress and serum biochemical markers of cellular damage in healthy subjects. Ann Nutr Metab. 2008;53(3-4):175-181

[34] Rakicioğlu N, Samur G, Topcu A, Topcu AA. The effect of ramadan on maternal nutrition and composition of breast milk. Pediatr Int. 2006;48(3):278-283

[35] Machlin LJ(Ed.). Handbook of vitamins. New York:Marcel Dekker Inc;1984

[36] Bendich A. Vitamin C safety in humans. New York:Marcel Dekker Inc;1997

[37] Temple NJ. Antioxidants and disease: more questions than answers. Nutr es. 2000;20(3):449-459

[38] Willet WC. Diet and health: what should we eat? Science. 1994;264(5158):532-537

[39] Willet WC. Diet, nutrition, and avoidable cancer. Environ Health Perspect. 1995;103/Suppl 8):165-170 